\title{
Scheimpflug-Placido Disk Topografi ile Sağlıklı ve Sistemik Arteryel Hipertansiyon Hastalarında Fakoemülsifkasyon Öncesi ve Sonrası Pupil Çapının Değerlendirilmesi
}

\section{Evaluation of Pupil Diameter Before and After Phacoemulsification in Healthy and Systemic Arterial Hypertension Patients with Scheimpflug-Placido Disc \\ Topography}

\author{
Yakup GÜNEŞ $^{1-(D)}$, Ali şiMŞEK $^{2}$ (D), Müslüm TOPTAN ${ }^{2}$ (D) \\ ${ }^{1}$ Batman Bölge Hastanesi Göz Kliniği,Batman, Türkiye \\ 2 Harran Üniversitesi Tıp Fakültesi, Göz Hastalıkları AD, Şanlıurfa, Türkiye
}

Öz.

Amaç: Sağlıklı ve sistemik arteriyel hipertansiyonu olan hastalarda fakoemülsifikasyon cerrahisi öncesi ve sonrası pupil çapının değişimini Scheimpflug-Placido Disk Topografisi (Sirius, CSO Inc.) ile değerlendirmeyi amaçladık.

Materyal ve metod: Bu çalışmada fakoemülsifikasyon planlanan 75 sağlıklı ve 77 sistemik arteriyel hipertansiyon (HT) hastası alındı. Pupil çapı (PÇ) ameliyat öncesi ve ameliyattan 1 ay sonra Kombine Scheimpflug-Placido Disk Topografisi pupillometresi ile ölçüldü. Grupların ameliyat öncesi ve ameliyat sonrası pupil çapı değerleri karşılaştırıldı.

Bulgular: Sağlıklı grupta ameliyat öncesi ve sonrası pupil çapı değişimi anlamlı bulundu $(5,13 \pm 1,38$ $\mathrm{mm}$ ve $3,07 \pm 0,52 \mathrm{~mm}$ sırasıyla. $p<0,05)$. HT grupta ameliyat öncesi ve sonrası pupil çapı değişimi anlamlı bulundu $(5,26 \pm 1,39 \mathrm{~mm}$ ve $3,14 \pm 0,51 \mathrm{~mm}$ sırasıyla. $\mathrm{p}<0,05)$. Sağlıklı ve HT gruplarında PÇ değişiminin etki değerleri farklı bulundu (1,48; 1,77 sırasıyla).

Sonuç: Fakoemülsifikasyon sonrası iki grupta PÇ azaldı. Fakoemülsifikasyon cerrahisinin HT hastalarında PÇ değişimi, sağııklı gruba göre daha fazla olduğu izlenmektedir. Bu değişimi HT hastalar'da yapılacak refraktif cerrahi palanlarken göz önüne alınması önemli olacaktır.

Anahtar Kelimeler: Fakoemülsifikasyon, Pupil Çapı, Topografi

Abstract

Background: We aimed to evaluate the change of pupil diameter before and after phacoemulsification surgery in patients with healthy and systemic arterial hypertension with Scheimpflug-Placido Disc Topography (Sirius, CSO Inc.).

Materials and Methods: This study included 75 healthy and 77 systemic Arterial Hypertension (HT) patients scheduled for phacoemulsification. Pupil Diameter (PD) was measured by combined Scheimpflug-Placido Disc Topography pupillometer before and 1 month after surgery. The preoperative and postoperative pupil diameter values of the groups were compared.

Results: In the healthy group, the change of pupil diameter before and after surgery was significant $(5.13 \pm 1.38 \mathrm{~mm}$ and $3.07 \pm 0.52 \mathrm{~mm}$, respectively. $p<0.05)$. In the HT group, the change of pupil diameter before and after surgery was significant $(5.26 \pm 1.39 \mathrm{~mm}$ and $3.14 \pm 0.51 \mathrm{~mm}$, respectively. $p<0.05)$. The effect values of PS change in healthy and HT groups were found different $(1.48 ; 1.77$ respectively).

Conclusion: PD decreased in two groups after phacoemulsification. It is observed that phacoemulsification surgery is more prominent in HT patients than in the healthy group. It will be important to consider this change when planning refractive surgery in HT patients.

Key words: Phacoemulsification, Pupil Diameter, Topography.
Sorumlu Yazar / Corresponding Author

Doç. Dr. Ali Şimşek, Harran Üniversitesi Tıp Fakültesi, Göz Hastalıkları Anabilim Dalı, 63000 Şanlıurfa, Türkiye.

e-mail: alisimsek1980@gmail.com

Geliş tarihi / Received:

19.07.2020

Kabul tarihi / Accepted: 25.04.2021

DOI: 10.35440/hutfd.771443 


\section{Giriş}

Ön segment parametrelerinden pupil çapının (PÇ)değerlendirilmesi oftalmik muayenenin önemli bir parçasıdır. Klinik uygulamada, ön segmentin görüntülenmesi geleneksel olarak yarık lamba biyomikroskopisi ile gerçekleştirilir, ancak parametrelerinin objektif değerlendirmesi sınırlıdır. Bununla birlikte güncel görüntüleme yöntemlerinden olan Scheimpflug kamera sistemleri; korneanın ön ve arka yüzeylerinin, ön kamara derinliğinin, pupil çapı, ön kamara açısı, iris ve merceğin objektif olarak değerlendirme imkanını bize sunar (1).

Modern hayatta PÇ değerlendirilmesi hastaların görme beklentisini tahmin etme açısından önem arz etmektedir (2). Psödofakik hastalarda görme kalitesini daha iyi anlamak için katarakt cerrahisinin PÇ değişiklik yaptığını bilmek önemlidir. Psödofakik hastalarda PÇ kamaşma $(3,4)$, görüntünün uyum mesafesi $(5,6)$, binoküler görme keskinliği (7) ve çok odaklı bir göz içi lensi (GiL) ile uzak ve yakın görme keskinlikleri gibi çeşitli görsel fonksiyonlarla ilişkili olduğu iyi bilinmektedir (8).

Yapılan güncel çalışmalarda katarakt ameliyatından sonra pupil şekli ve cevabının sıklıkla değiştiği bulunmuştur $(9,10)$. Özellikle bazı intrakapsüler ve ekstrakapsüler katarakt ekstraksiyonundan sonra sabit bir dilate pupilla ortaya çıkar (11). Ayrıca Koch ve ark., ameliyat sonrası PÇ ameliyat öncesi büyüklükle orantılı korelasyon göstermediği bildirmektedir (12).

Katarakt cerrahisi sonrası PÇ ve şeklindeki değişikliklerde, kullanılan cerrahi teknikler, gözü etkileyen sistemik bir hastalığın varlığı ve hastanın kullandığı ilaçlar önemli olduğundan dolayı, hangi hastaların multifokal GiL implantasyonu için en uygun olduğunu seçmek zordur (13).

Biz bu çalışmada fakoemülsifikasyon cerrahisi uygulanan sağlıklı ve sistemik arteriyel hipertansiyon hastalarında ameliyat öncesi ve sonrası PÇ değişiklikleri inceledik. Ameliyat öncesi ve sonrası PÇ arasında bir korelasyon olup olmadığını değerlendirdik

\section{Materyal ve Metod}

$\mathrm{Bu}$ geriye dönük olarak planlanan bu çalışma Batman Bölge Devlet Hastanesi Göz Hastalıkları kliniğinde 01/01/2019 ile 12/15/2019 tarihleri arasındaki dosyalar çalışmaya alındı. Çalışma için Batman Bölge Devlet Hastanesi Etik Kurulu'ndan etik onam alındı (21.01.2020 tarihli, karar no:225). Tüm araştırma Helsinki deklarasyonu kurallarına uygun şekilde yürütüldü. Bu çalışmada fakoemülsifikasyon yapılan ve sorunsuz fakoemülsifikasyon ameliyatı geçiren 75 sağlıklı ve 77 sistemik arteriyel hipertansiyon (HT) hastası alındı. İskemik optik nöropati, diğer optik sinir hastalığı, retinal arter tıkanıklığı, retinal ven tıkanıklığı, glokom öyküsü, serebrovasküler inme veya geçici iskemik atak, iris neovaskülarizasyonu, iris atrofisi veya asimetrik şekilli pupillası olan hastalar çalışma dışı tutuldu. Fundus muayenesine ve retina patolojiyi sınıflamaya engel olacak düzeydeki kataraktı olanlar çalışma dışı bırakıldı. Ayrıca miyopik, hipermetropik ve astigmatik kırılma kusurları \pm 1.0 D'den büyük olan hastalar da dışlandı. Kataraktı kortikal lens opasiteleri 2+ 'den büyük olan hastalar ve HT olan hastalar çalışmaya alındı. HT gurubunda, arterde hafif incelme olan (Derece 1 ) hipertansif retinopati hastaları çalışmaya dahil edildi. Kombine Kombine Scheimpflug-Placido Disk Sistemi (Sirius, CSO Inc.) ile sağlıklı ve sistemik arteriyel hipertansiyon hastalarında PÇ'nın fakoemülsifikasyon öncesi ve ameliyattan1 ay sonra ölçümler kayıt altına alındı. Aynı Teknisyen tarafından yapılan ölçümler alındı. Tüm ölçümler standart loşışık koşullarında elde edilmiştir. Sirius yeni bir topografi cihazıdır. Cihaz monokromatik 360 derece rotasyon yapan Scheimpflug kamera ve 22 halkalı Placido-diski kombine eder, kornea ve ön kamaradan 25 radial kesit alır. Tek bir kesitte kornea ön ve arka yüzeyinin tanjansiyel ve aksiyel kurvatür bilgisini sağlar, korneanın global refraktif gücünü verir, çoğu göz içi yapıların biometrik ölçümlerini verir. Kornea ön yüzeyinden 35632 nokta ve kornea arka yüzeyinden 30000 nokta 475 nm mavi led ışığı ile inceleni. Bir taramayı tamamladıktan sonra, birçok ön kamara parametreleri ile beraber $P C^{\prime}$ da bize verir.

Tüm ameliyatlar lokal anestezi altında aynı cerrah tarafından ve CENTURION ${ }^{\circledR}$ Vision System (Phacoemulsification System, Alcon, US) cihazıyla yapıldı. Tüm hastalara AcrySof IQ Monofocal IOL (Alcon Inc, US) takıldı.

İstatistiksel analiz, Windows Sürüm 15.0 (Spss Inc., Chicago, IL, ABD) için spss ile gerçekleştirildi. Tüm veriler ortalama \pm standart sapma (SD) olarak bildirildi. Bir grupta devam eden değişkenler için normallik Shapiro-Wilks testi ile belirlendi. Değişkenler normal dağılım gösterdi ( $p>$ 0.05). Bu nedenle, ameliyat öncesi ve sonrası dönemler arasındaki değişkenleri karşılaştırmak için eşleştirilmiş ttesti kullanıldı. İlişkileri değerlendirmek için Pearson'un korelasyon testi kullanıldı. Değişkenler arasında $\mathrm{P}<0.05$ değeri istatistiksel olarak anlamlı kabul edildi. Ameliyatın gruplar üzerindeki etki değeri hesaplandı (Etki büyüklüğü değeri $d=t / \sqrt{ } n$ veya $d=o r t a l a m a l a r$ arası fark/ortalamalar arası farkın std. Deviation). Etki değerinin büyümesi, PÇ'nın ameliyattan daha çok değiştiğini gösterir.

\section{Bulgular}

Hipertansiyon grubunun $35^{\prime}$ ü (45.5\%) kadın ve $42^{\prime} \mathrm{i}$ (54.5\%) erkek iken kontrol grubunun 35'ü (46.7\%) kadın ve 40 'si (53.3\%) erkek idi. Hipertansiyon grubunun yaş ortalaması $63,03 \pm 5,73$ yıl ve kontrol grubunun $65,27 \pm 9,051 y ı l$ idi. İki grup arasında yaş ve cinsiyet açısından istatistiksel olarak fark yoktu. ( $p>0,05)$.

Sağlıklı ve hipertansiyon grubunun ameliyat öncesi ve ameliyat sonrası PÇ Şekil 1' de görülmektedir. Sağııklı grupta ameliyat öncesi ve sonrası PÇ değişimi anlamlı bulundu $(5,13 \pm 1,38 \mathrm{~mm}$ ve $3,07 \pm 0,52 \mathrm{~mm}$ sırasıyla. $p$ $<0,05)$. HT grupta ameliyat öncesi ve sonrası PÇ değişimi anlamlı bulundu $(5,26 \pm 1,39 \mathrm{~mm}$ ve $3,14 \pm 0,51 \mathrm{~mm}$ sırasıyla. $p<0,05)$. Sağlıklı ve HT guruplarında PÇ değişiminin etki değerleri farklı bulundu (Sırasıyla 1,48 ve 1,77 sırasıyla). 


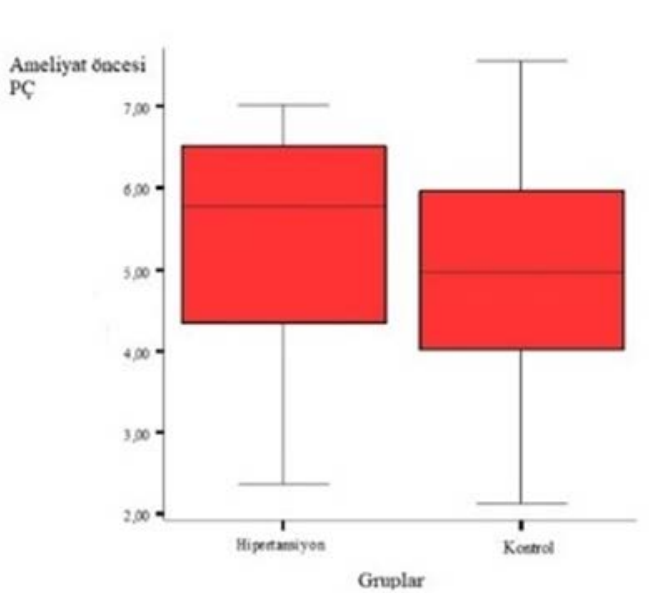

a

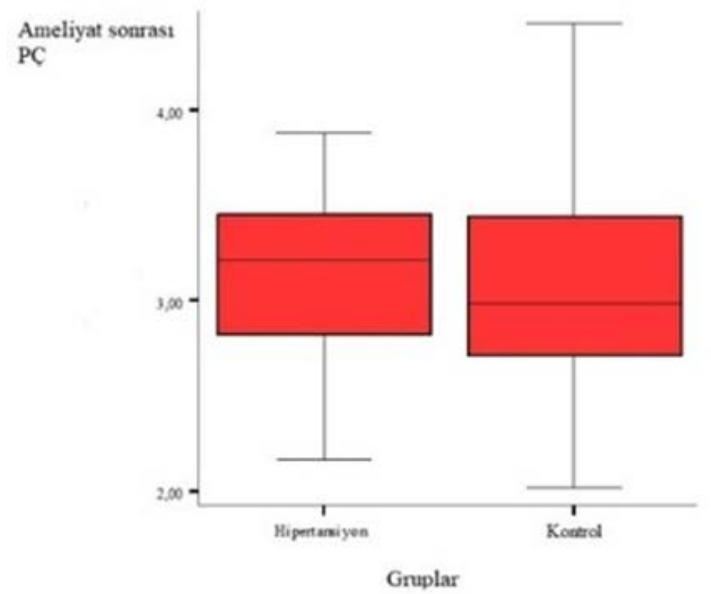

b

Şekil 1. Grupta ameliyat öncesi (a) ve ameliyat sonrası(b) pupil çapı. PÇ; Pupil Çapı

\section{Tartışma}

Pupil çapı uyaranın parlaklığına ve diğer çeşitli faktörlere bağlı olarak değişir. PÇ görsel fonksiyon üzerindeki önemli etkiye sahiptir (14). Pupil çapı ve şekli, alan derinliği ve ayrıca retinal aydınlık üzerinde doğrudan bir etkiye sahiptir. Bu durumda doğrudan görsel performansı etkiler. Klinik uygulamadaki pupillometri sistemlerinin çoğu, pupil görüntüsünü yakalamak için yakın kızıl ötesi aydınlatma kullanır (15). Çoğu sistemde bu durum ortak bir özelliktir. Çaıışma şekli bir ışık kaynağı ile doğrudan göz aydınlatılması ve ardından kızıötesine yakın bir kamera ile pupil görüntüsü yakalanmasıdır (16).

Çalışmamız HT hastalarında katarakt cerrahisinin PÇ üzerinde etkileri değerlendirmiştir. Katarakt cerrahisini takiben PÇ değişiklikleri hakkında literatürde çalışmalara mevcuttur. Bu çalışmalarda multifokal GiL gibi farklı koşullarda PÇ’a (12), arka kamara fakik GiL'ler (17), iris fiksasyonlu Gí'ler ve diyabetes mellituslu hastalar (18) PÇ üzerindeki etkisine bakılmıştır. Bu çalışmalarda katarakt cerrahisini takiben PÇ ve şeklinde istatistiksel olarak anlamlı bir değişiklik olduğu görülmüş ve ameliyat sonrası PÇ küçülme ortalaması \%11 ile \%13 arasında tespit edilmiştir (19). PÇ değişiklikleri, hacimli kristal lensin çıkarılmasından sonra artan AC derinliği ve hacmi ile ilişkili olabilir. Bir diğer faktör ortalama kalınlık $4.4 \mathrm{~mm}$ olan lensin daha ince bir IOL ile değiştirmesidir (20). Ön segmentte değişen bu parametreler azaltılmış IOL hacim, daraltıcı iris kaslarının daha fazla hareket serbestliğine izin verebilir ve bu durum iris kaslarının tam kasılmasını sağlayarak PÇ küçültür. Katarakt ameliyatından sonra bu tür kısıtlamaların radikal olarak azaltılması (hatta ortadan kaldırılması) daha dairesel (daha az eksantrik) pupil büyüklüğüne katkıda bulunan bir faktör olabilir. Katarakt ameliyatından sonra daha dai- resel (daha az eksantrik) pupil büyüklüğüne katkıda bulunan bir faktör olabilir. Bizim çalışmamızda hem sağlıklı grupta hem de HT grupta PÇ'ı postoperatif değerleri istatistiksel olarak düşmüştür ve $\mathrm{HT}$ hastalarında etkisi daha büyük olmuştur. Bizim çalışmamızda HT hastalarında da bakılması çalışmamızı farklı kılıyor.

Literatürler incelendiğinde, HT gibi sistemik etkileri olan Diyabet hastalığının pupillaya etkileri daha önce birçok çaIışmada ayrıntılı biçimde incelendiği halde, HT'nun etkisini inceleyen çalışmalara ulaşamadık. Diyabetin mikroanjiopati yaptığı bunun sonucu olarak nöropati yaptığını biliyoruz. Diyabetik nöropati, DM'un yaygın ve ciddi komplikasyonlarından biridir (21). Diyabetik otonomik nöropati istemsiz-otonomik sinirsel kontrolün bulunduğu tüm doku ve organlarda kendini gösterebilir, sempatik ve/veya parasempatik sinirleri etkileyebilir (22). Gözle ilgili otonomik nöropatiler, pupilla bozuklukları, gözyaşı salgısında ve kornea duyarlılığında azalmayı içerir (23). Diyabete bağlı pupiller otonomik nöropati hemen daima pupillanın normale kıyasla küçük olmasıyla kendini gösterir. Diyabetik küçük pupilla, sempatik sinirlerdeki hasara bağlı olarak, otonomik dengenin parasempatikler lehine bozulması sonucunda ortaya çıkar (24). Diyabetik hastalarda sempatik iris innervasyonunun daha hassas olması, bu sinir yolunun daha uzun olmasından kaynaklanabilir (25). Hipertansiyon da diyabetten farklı olarak damar cidarında elastik laminanın kalınlaşması ve hiyalin değişiklikleri dahil olmak üzere kan damarlarında fiziksel değişikliklere neden olan bir mikroanjiopatiye neden olur. Kan damarlarının doğrudan görülebildiği göz dokularında hipertansiyon ile ilişkili değişiklikler aşağıdaki gibi görülebilir ve derecelendirilebilir. Hipertansif retinopati, retinal vasküler oklüzyon, retinal makroanevrizma ve iskemik optik nöropatiyi içerir. Hipertansiyon, Diyabetik Retinopatinin (DR) görme tehdit 
edici etkilerini de şiddetlendirebilir ve yaşa bağı makula dejenerasyonunun gelişiminde bir risk faktörü olarak gösterilmiştir (26).

Hipertansiyonun DR gelişiminde ve ilerlemesinde bağımsız risk faktörü olduğu gösterilmiştir. Bu otomatik düzenleme diyabet hastalarında bozulmakta, böylece hipertansiyonun DR üzerindeki zararlı etkisi için bir mekanizma sağlamaktadır (27). HT hasta grubunda diyabete benzer bir şekilde, sempatik sinirlerdeki hasara bağlı olarak, otonomik dengenin parasempatikler lehine bozulması meydana gelmiş olabilir. Bu durumun PÇ değişimi üzerindeki etkinin daha büyük olmasını açıklayabileceğini düşünüyoruz.

Katarak cerrahisinde daha iyi sonuçlara ulaşmak için yoğun çaba içinde olduğumuz bu zaman diliminde; katarakt cerrahisi planladığımız HT'lu hastalardaki PÇ değişiminin tahmin edile bilmesi önemlidir. Hastaların Görme beklentisi ve doğru lens secimize yardımcı olabilir.

Kataraktan sonra HT ve sağlıklı grupta da PÇ azaldığını gözlemledik. Katarakt cerrahisinin HT hastalarında PÇ değişimi sağlıklı hasta gurubuna göre daha fazla olduğu gözlemledik. HT hastalar'da yapılacak katarak cerrahi palanlarken göz önüne alınması önemli olacaktır.

Etik onam: Çalışma için Batman Bölge Devlet Hastanesi Etik Kurulu'ndan etik onam alındı (21.01.2020 tarihli, karar no:225). Yazar Katkıları:

Konsept: Y.G., A.Ş.

Literatür Tarama A.Ş., M.T.

Tasarımı: A.Ş.

Veri toplama: Y.G.

Veri analizi ve yorumlama: A.Ş., M.T.

Makale yazımı: A.Ş.

içeriğin eleştirel incelenmesi: Y.G., A.Ş.

Çıkar Çatışması: Yazarlar çıkar çatışması beyan etmemişlerdir. Finansal Destek: Yazarlar finansal destek beyan etmemişlerdir.

\section{Kaynaklar}

1. Rabsilber TM, Khoramnia, Auffarth GU. Anterior chamber measurements using Pentacam rotating Scheimpflug camera. J Cataract Refract Surg. 2006;32: 456-59.

2. Koch DD, Samuelson SW, Haft EA, Merin LM. Pupillary size and responsiveness implications for selection of a bifocal intraocular lens. Ophthalmology.1991;98:1030-35.

3. Koch DD, Jardeleza TL, Emery JM, Franklin D. Glare following posterior chamber intraocular lens implantation. J Cataract Refract Surg. 1986; 12:480-84.

4. Masket $S$. Relationship between postoperative pupil size and disability glare. J Cataract Refract Surg. 1992; 18: 506-07.

5. Nakazawa M, Ohtsuki K. Apparent accommodation in pseudophakic eyes after implantation of posterior chamber intraocular lenses: optical analysis. Invest Ophthalmol Vis Sci.1984; 25:1458-60.

6. Elder MJ, Murphy C, Sanderson GF. Apparent accommodation and depth of field in pseudophakia. J Cataract Refract Surg. 1996; 22:615-19.

7. Obara $\mathrm{Y}$, Hashi H, Tonaki M, Yoshida S. Causes of binocular dysfunction in pseudophakic eyes[Japanese]. Jpn IOL Soc J. 1989; 3:59-63.
8. Ravalico G, Baccara F, Bellavitis A. Refractive bifocal intraocular lens and pupillary diameter. J Cataract Refract Surg. 1992; 18:594-97.

9. Gibbens MV, Goel R, Smith SE. Effect of cataract extraction on the pupil response to mydriatics. Br J Ophthalmol. 1989; 73:56365.

10. Yap EY, Aung T, Fan RFT. Pupil abnormalities on the first postoperative day after cataract surgery. Int Ophthalmol. 1996; 20:187-92.

11. Golnik KC, Hund PW, Apple DJ. Atonic pupil after cataract surgery. J Cataract Refract Surg. 1995; 21:170-75.

12. Koch DD, Samuelson SW, Villarreal R, Haft EA, Kohnen T. Changes in pupil size induced by phacoemulsification and posterior chamber lens implantation: consequences for multifocal lenses. J Cataract Refract Surg. 1996; 22:579-84.

13. Zaczek A, Zetterstro"m C. Cataract surgery and pupil size in patients with diabetes mellitus. Acta Ophthalmol Scand. 1997; 75:429-32.

14. Watson AB, Yellott JI. A unified formula for light-adapted pupil size. J Vis. 2012;12(10):12.

15. Lee JC, Kim JE, Park KM, Khang G. Evaluation of the methods for pupil size estimation: on the perspective of autonomic activity. Conf Proc IEEE Eng Med Biol Soc. 2004;2:1501-04.

16. Roberts DK, Yang Y, Lukic AS, Wilensky JT, Wernick MN. Quantification of pupil parameters in diseased and normal eyes with near infrared iris transillumination imaging. Ophthalmic Surg Lasers Imaging. 2012; 43(3):196-204.

17. Keuch RJ, Bleckmann H. Pupil diameter changes and reaction after posterior chamber phakic intraocular lens implantation. J Cataract Refract Surg. 2002;28(12):2170-72.

18. Dick HB, Aliyeva S, Tehrani M. Change in pupil size after implantation of an iris-fixated toric phakic intraocular lens. J Cataract Refract Surg. 2005;31(2):302-07.

19. Totsuka K, Kato S, Shigeeda T, Honbo M, Kataoka Y, Nakahara $\mathrm{M}$ et al. Influence of cataract surgery on pupil size in patients with diabetes mellitus. Acta Ophthalmol. 2012;90(3):23739.

20. Holladay JT, Praeger TC. Accurate ultrasonic biometry in pseudophakia. Am J Ophthalmol. 1989;107(2):189-90.

21. Arıng A, Jones D, Falko J. Evaluation and prevention of diabetic neuropathy. Am Fam Physician. 2005;7:2123-30.

22. Vinik Al, Stansberry KB, Nakave AA, Patel CV. Diabetic neuropathy in older adults. Clin Geriatr Med 2008;24:407-39.

23. Jacobson DM. Pupil involvoment in patients with diabetesassociated oculomotor nevre palsy. Arch Ophthalmol. 1998;116:723-7.

24. Smith SE, Smith SA. Reduced pupillary light reflexes in diabetic autonomic neuropathy. Diabetologia. 1983;24:330-2.

25. Ishikawa S, Bensaoula T, Uga S, Mukuno K. Electron microscopic study of iris nerves and muscles in diabetes. Ophthalmologica. 1985;191:17283.

26. Fraser-Bell S, Symes R, Vaze A. Hypertensive eye disease: a review. Clin Exp Ophthalmol. 2017;45(1):45-53.

27. Rassam SM, Patel V, Kohner EM. The effect of experimental hypertension on retinal vascular autoregulation Hypertensive eye disease: a review 51 in humans: a mechanism for the progression of diabetic retinopathy. Exp Physiol. 1995; 80: 53. 